\title{
Learning Strategies in Self-directed Language Learning Using Mobile Technology in Higher Education: A Systematic Scoping Review
}

\author{
Yuzhi Lai $^{1}$ (D) Nadira Saab ${ }^{1} \cdot$ Wilfried Admiraal $^{2}$
}

Received: 2 December 2021 / Accepted: 6 February 2022 / Published online: 22 February 2022

(c) The Author(s) 2022

\begin{abstract}
Language learners in higher education increasingly use out-of-class self-directed learning facilitated by mobile technology. In order to make informed educational decisions, this study sets out to provide an overview of empirical research into learning strategies that self-directed learners use with the support of mobile technology in language learning. Twenty studies were selected and systematically analysed, revealing the cognitive, metacognitive, social and affective strategies that selfdirected learners used in their language learning processes. Low-cognitive strategies appeared to be more commonly reported than high-cognitive strategies. The use of metacognitive strategies was more closely associated with the forethought phase and performance phase than with the self-reflection phase, yet only a few articles reported all three metacognitive phases. Three kinds of social strategies were examined, and only one affective strategy was reported. Finally, implications of these findings and directions for future research are provided for self-directed learners, practitioners and researchers to facilitate self-directed learning and future work.
\end{abstract}

Keywords Self-directed language learning $\cdot$ Mobile-assisted learning $\cdot$ Learning strategies $\cdot$ Higher education $\cdot$ Review

Yuzhi Lai

y.lai@iclon.leidenuniv.nl

Nadira Saab

n.saab@iclon.leidenuniv.nl

Wilfried Admiraal

w.f.admiraal@iclon.leidenuniv.nl

1 ICLON, Leiden University Graduate School of Teaching, Leiden University, Kolffpad 1, 2333 AL Leiden, The Netherlands

2 Centre for the Study of Professions, Oslo Metropolitan University, PO Box 4 St. Olavs plass, N-0130 Oslo, Norway 


\section{Introduction}

The globalisation of economies and societies has consequences regarding the need to learn foreign languages for international communication, especially for academic and business purposes (Kramsch, 2014). These foreign language competencies are specifically relevant for students who attend courses abroad, either on campus or online, and academics who choose to work in an international context. In higher education, however, there is not much space to learn foreign languages as part of the subject curriculum in a discipline, and in some countries students do not receive enough in-class language exposure to ensure their learning success (Richards, 2015; Trinder, 2017; Tsou et al., 2006). Many students therefore try to improve their foreign language competencies outside the curriculum, in a self-directed way. Students use, for example, mobile apps such as HelloTalk, Twitter, YouTube, et cetera, to create their own learning environment (Lai et al., 2022). They may receive support from teachers, but the process is studentinitiated and self-directed (Lai et al., 2022). Self-directed learning broadly refers to the process in which individuals take responsibility and initiative over their own learning process, including diagnosing the learning needs, designing the learning plan, identifying human and material resources for learning, choosing and implementing appropriate learning strategies, and evaluating their learning results, with or without others' help (Knowles, 1975; Merriam \& Bierema, 2013). Many researchers use self-directed learning interchangeably with self-regulated learning (Loyens et al., 2008). Although their definitions are similar and both involve active engagement and goal-directed behaviour, the difference lies in the degree of control the learners have, specifically at the beginning of the learning process (Loyens et al., 2008). In self-directed learning, learners are the initiators of the learning tasks, whereas in self-regulated learning, they are not. In order to support this kind of self-directed learning, students can use mobile technology to learn foreign languages (e.g., Lai \& Gu, 2011; Zhang \& Pérez-Paredes, 2019). Mobile technology, which is defined as mobile phones, tablets, laptops and possible applications on them, has become popular due to its easy access to abundant resources and convenient connection with others, so students utilise it to develop their language competence in the authentic environment and maintain their interests in learning. However, adopting any learning approach or mobile technology does not guarantee successful learning (Vogel et al., 2009). How students conduct the learning process also matters, which may benefit from further research on improving the effectiveness of such learning experiences.

To date, most reviews on self-directed learning are not about student-initiated learning, but on self-regulated learning instead (e.g., Dent \& Koenka, 2016; Jansen et al., 2019). Given the significance of this kind of learning approach, research on student-initiated self-directed learning outside class deserves more attention. For this reason, we conducted a review of self-directed language learning using mobile technology beyond the classroom, which could inform self-directed learners, educators and software developers on how to effectively enhance self-directed learning with mobile technology. 


\section{Self-directed use of mobile technology in language learning}

In order to increase the opportunities to expose to foreign languages, learners use mobile technology as an instrument to learn foreign languages in an out-of-class and self-directed way (Lai et al., 2022). The characteristics of mobile technology, such as portability, individuality, social connectivity, and context sensitivity, have been broadly incorporated in language learning (Chinnery, 2006). Concerning portability, learners can use mobile technology to convenient and continual access to language resources and practice opportunities anytime and anywhere via applications such as Google or YouTube because mobile technologies are easily carried (Sung et al., 2015). Supported by its feature of individuality, mobile technology enables learners to personalize and customize the learning process based on their own needs and interest. About social connectivity, learners use mobile apps such as Skype and HelloTalk to collaborate or share with other language learners and native speakers in the target language, either synchronously or asynchronously (Lan et al., 2007). Regarding its context sensitivity, mobile technology allows learners to integrate language knowledge with real life and cultural context (Chen \& Li, 2010). However, using mobile technology in learning does not guarantee successful learning (Vogel et al., 2009). Learners still need to employ appropriate strategies to support their language learning process.

A number of review studies regarding learning strategies in self-directed use of technology have been performed. Yet as mentioned above, most of these review studies are about self-regulated learning instead of self-directed learning missing the self-initiated element. In online learning setting, for example, Broadbent and Poon (2015) examined self-regulated strategies as correlates of academic outcomes in higher education through a review of 12 studies. They concluded that critical thinking, effort regulation, time management, metacognition, and peer learning were all positively related to learning outcomes, whereas the relationships with organisation, elaboration, and rehearsal were the least empirically supported. In addition, Stevenson et al. (2017) performed a meta-analysis of 17 studies to assess how concept mapping-based technologies (including computer software, mobile devices, web-based learning environment and electronic system) impacted selfregulated learning through various strategies. The findings showed that computer software was useful for developing cognitive strategies, teachers could stimulate metacognitive strategies, and both mobile technologies and teachers could help to enhance motivation. In the field of e-learning, Garcia et al. (2018) reviewed 19 articles to investigate whether learning self-regulated strategies could be supported by modern technologies in high school. The findings reported that selfevaluation and seeking information were the most researched categories, while seeking social assistance and environmental structuring were not examined in any study. Also, another review was conducted by Lee et al. (2019) to analyse 21 empirical articles published from 2008 to 2016 regarding self-regulated learning in MOOCs. The results showed that self-regulated learning positively correlated with learning in MOOCs, and contextual, behavioural, metacognitive, and motivational regulation strategies were identified. And in 2020, Anthonysamy 
et al. (2020) reviewed 14 articles on how self-regulated learning strategies in a blended learning environment were related to positive non-academic outcomes. The results showed that these strategies were positively related to non-academic outcomes. Motivational belief strategies, resource management, and metacognitive knowledge were investigated most, whereas cognitive engagement strategies were examined in only a few studies.

These reviews mentioned above were mainly about online courses, specific technologies, electronic tools or a blended learning environment, which were broader than mobile technology. Given the features of mobile technology in language learning claimed above, this study focused on just mobile technology. Additionally, although these reviews added understanding to the self-directed learning strategies using technology, they did not differentiate between teacherinitiated or student-initiated, nor in class or out of class learning. Considering the popularity of students-initiated exposure to foreign languages outside class and the significance of self-directed learning approach, it is essential to understand how students conduct their learning in a self-initiated and out-of-class way. Moreover, these above-mentioned strategies examined in previous review studies are not about foreign language learning. Specific strategies in foreign language learning need to be investigated, which could be conducive to foreign language learners and provide practical guidance for future investigations. To fill in these gaps, this study gained an insight into the learning strategies that university students used in their out-of-class self-directed language learning process.

Previous research has indicated that strategies played a vital role in language learning process and success. In the current study, learning strategies refer to behaviours which could "help learners to comprehend" (O'Malley \& Chamot, 1990), "make learning easier, faster, more enjoyable, more self-directed, more effective, and more transferable" (Oxford, 1990), "mediate their own learning" (Hall, 2001), and finally enhance their language proficiency and boost confidence when using the language (Rusnadi, 2017). Qingquan et al. (2008) stated that research into learning strategies indicated that overall language performance was related to the level of strategy use. Effectively using learning strategies can improve learners' language competencies and make them better learners (Hismanoglu, 2000). In the domain of language learning, O'Malley et al. (1985a) divided learning strategies into three categories based on the type or level of processing involved, namely cognitive, metacognitive and affective/social strategies, which is acknowledged to be the "full range of strategies" (O'Malley \& Chamot, 1990, p. 44). Hsiao and Oxford (2002) proposed that the latter category should be further differentiated into social and affective strategies in order to increase the explanatory power of the original model. The final typology thus comprises the following four main components (O'Malley \& Chamot, 1990):

1. Cognitive strategies mean mentally processing learning materials, such as auditory representation, imagery, repetition, grouping, inferencing, translation, resourcing, deduction, summarising, recombination and note taking; 
2. Metacognitive strategies are associated with analysing planning, monitoring, and evaluating the learning process, such as selective attention, advance organisers, directed attention, self-management and self-evaluation;

3. Affective strategies involve managing the emotions, such as self-encouragement, self-reinforcement and self-talk, and

4. Social strategies concern interacting with people for the purpose of increasing the opportunities to practice foreign languages and get feedbacks, such as cooperation and questioning for clarification.

This scoping review gained an insight into students' learning strategies in selfdirected language learning using mobile technology. We thus investigated four research questions:

1. What cognitive strategies did students use during their self-directed language learning using mobile technology?

2. What metacognitive strategies did students use during their self-directed language learning using mobile technology?

3. What affective strategies did students use during their self-directed language learning using mobile technology?

4. What social strategies did students use during their self-directed language learning using mobile technology?

\section{Method}

The guidelines employed in this scoping review study were the Preferred Reporting Items for Systematic Reviews and Meta-analyses (PRISMA) extension for Scoping Reviews (Tricco et al., 2018).

\subsection{Data search}

Utilising PRISMA (Moher et al., 2009) principles, this study began with an extensive search of the literature conducted using electronic searches and the snowballing method to retrieve relevant literature. The federated search service provided by the library of a research university in the Netherlands was used for the electronic search. It is a comprehensive database, whose sources include, amongst others, Web of Science, Taylor and Francis, Elsevier/ScienceDirect and EBSCOhost. Three sets of keywords were used: (1) self-directed-learning related keywords, including selfdirected, SDL, self-regulated, SRL, "out of class", autonomous, informal, and ubiquitous; (2) technology-related keywords, including mobile and technology; and (3) foreign-language related keywords, including "language learning", "English learning", and "foreign language learning". When searching the electronic database, the three sets of keywords were combined. The search was conducted in February 2020, which served as the cut-off date for published articles. The articles had to be written in English and peer-reviewed. After collating all the relevant studies, the 
snowballing method was used to find more relevant work based on reference lists in the studies from the electronic search.

\subsection{Data selection}

On $10^{\text {th }}$ February 2020 the initial search yielded 342 articles that were related to self-directed learning and mobile technology. The title and abstract of each identified study were firstly screened for eligibility. The studies without full text and the studies unrelated to student learning were excluded, and 170 studies remained for future analysis.

Studies were included if they met these criteria:

- Students should use mobile technology, including mobile devices (laptop, smartphone, tablet) and applications on these devices, to support their learning.

- The learning tasks should be initiated and managed by the participants themselves, with or without teacher support, in the learning process.

- The learning content should be foreign languages.

- Involving students in higher education.

- Including the information on learning activities.

Ten percent of 170 articles were also read by a co-author based on the abovementioned inclusion criteria. There was a discrepancy about one article. The two researchers held a discussion, and finally consensus was reached. Applying these inclusion criteria reduced our database to 20 studies, 13 from electronic searches and 7 from the snowballing method. This literature search and review procedure is illustrated in Fig. 1. Regarding the method of data collection and analysis, among the 20 studies, 3 studies used quantitative method, 1 used qualitative method, 1 used action research, and 15 used mixed methods (quantitative and qualitative method).

\subsection{Data extraction and analysis}

Author name, publication year, participants' proficiency levels and learning activities were extracted from each study. Each article was checked to extract the learning activities from the results and conclusion sections. These texts were coded as learning strategies based on O'Malley's classification, namely, metacognitive, cognitive, affective and social strategies, and specific strategies are explained in the results section and Appendix A. For example, it was coded as Contextualisation, categorized in cognitive strategies, when participants learned new words and vocabulary in Facebook, as reported by Hamat and Abu Hassan (2019). These coded texts were sorted and summarised (See Appendix B). To ensure all relevant information extracted, 20 articles were double-checked by two researchers. When there were disagreements on the coding, these were discussed among researchers until the consensus was reached.

For data analysis, Bloom's revised taxonomy is employed as the framework to measure cognitive strategies in order to determine the level of students' thinking 


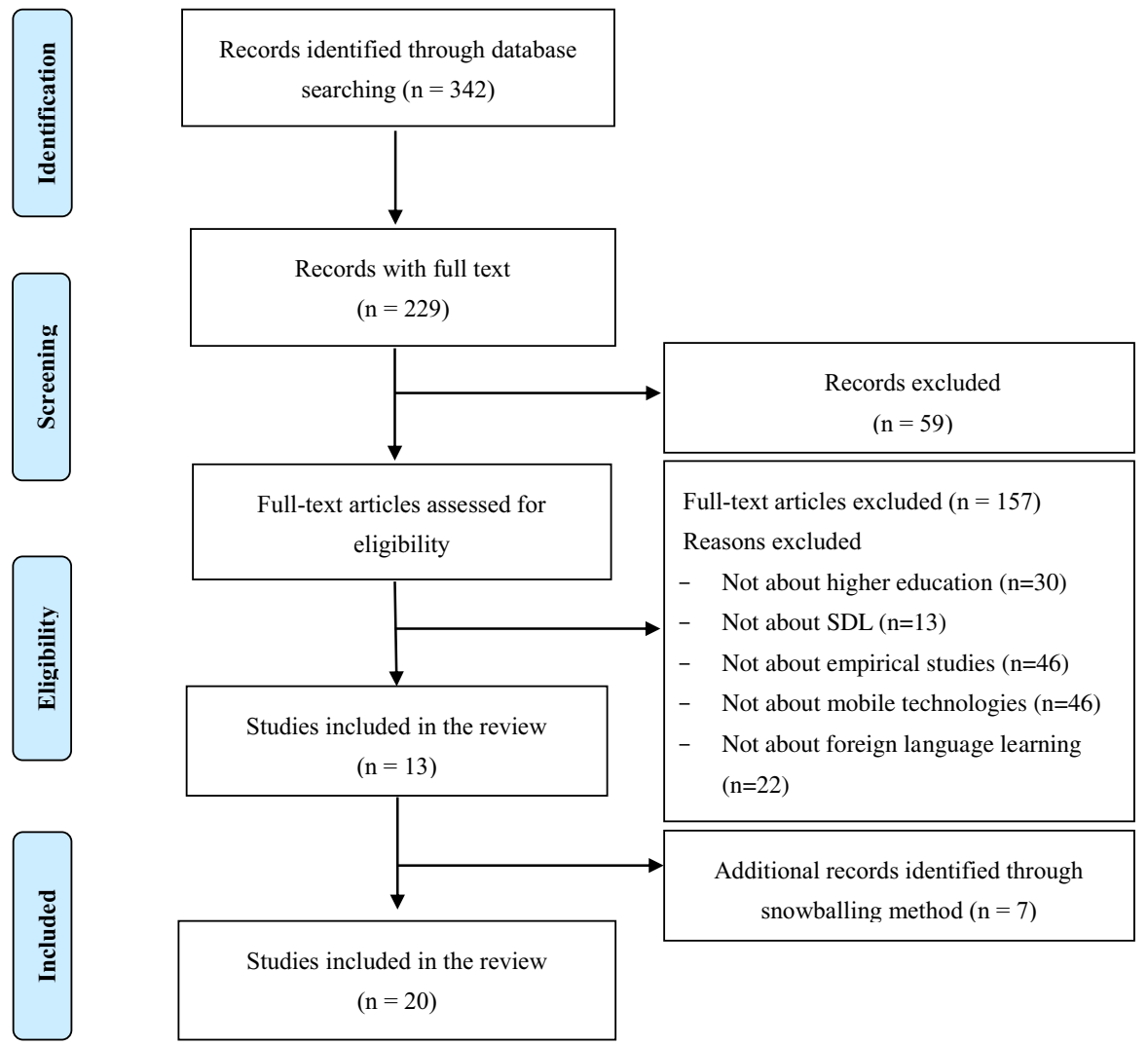

Fig. 1 Flow chart depicting the search and selection process. SDL denotes self-directed learning

(Anderson et al., 2001; Crompton et al., 2019). Anderson et al. (2001) categorized cognitive learning as six levels: 1) remembering, which refers to recalling and remembering basic facts and rules; 2) understanding, which means comprehending the meaning of information; 3) applying, which refers to executing knowledge, skills, or techniques in new situations; 4) analysing, which means breaking the information into its main parts; 5) evaluating, which means making judgments based on in-depth reflection; and 6) creating, which refers to creating new information. The six levels range from low-order, which requires less cognitive processing, to high-order, which requires deep learning and a greater degree of cognitive processing (Anderson et al., 2001). And, widely-accepted cyclical self-regulatory phases proposed by Zimmerman $(2000,2008)$ are selected as the framework to categorize metacognitive strategies so as to show how students regulate their learning process. The cyclical self-regulatory phases consist of forethought, performance and self-reflection. In the forethought phase, language learners can set learning goals, assess linguistic resources for language tasks, and plan how to reach these goals. In the performance phase, learners actually execute the task, monitor and regulate how 
they are progressing. Finally, in the self-reflection phase, learners assess how they have performed the task (Zimmerman, 2000).

\section{Results}

\subsection{Cognitive strategies}

Cognitive strategies refer to processing the learning resources mentally or physically, or employing specific techniques in learning tasks, such as deduction, imagery, auditory representation, resourcing, inferencing, translation, repetition, grouping, summarising, recombination, and note-taking (O'Malley \& Chamot, 1990). As mentioned above, cognitive learning is classified into six levels, including remembering, understanding, applying, analysing, evaluating, and creating, from low-order to high-order (Anderson et al., 2001). Based on the data extracted, we classified the specific strategies examined in the reviewed studies into one or two of the cognitive levels. The results are summarised in Table 1.

At the remembering level, the lowest cognitive level, eight kinds of learning strategies were identified. Imagery, auditory representation and contextualisation were the most frequently identified in the reviewed articles, followed by repetition, recombination, note-taking, resourcing and grouping. Imagery means learners utilize visual images to recite and understand new language contents or mentally represent problems (O’Malley \& Chamot, 1990). It was identified in six articles. Learners used it through vocabulary apps such as Duolingo and Baicizhan (García Botero et al., 2019; Steel, 2012; Zhang \& Pérez-Paredes, 2019) and digital flashcards (Lai, 2019; Lai et al., 2018) for vocabulary and grammar learning. Auditory representation refers to playing the sound of words, phrases, or sentences in the back of one's mind so as to assist in comprehending and recalling (O'Malley \& Chamot, 1990). This was also identified in six articles, and it was used to learn vocabulary with language learning apps (García et al., 2018; Lai et al., 2017; Steel, 2012; Zhang \& Pérez-Paredes, 2019), and practice pronunciation and speaking through musical videos and songs (Ma, 2017; Sockett \& Toffoli, 2012). Contextualisation refers to "assisting comprehension or recall by placing a word or phrase in a meaningful language sequence or situational context" (O'Malley \& Chamot, 1990, p.126). Five articles showed that learners used this strategy to learn new words, technical terms and specific expressions on Facebook (Hamat \& Abu Hassan, 2019), natural learning environments created on YouTube and Podcast (Lai, 2019; Ma, 2017), and virtual online communities (Sockett \& Toffoli, 2012). Repetition means learners intentionally practice and rehearse the words or phrases repeatedly (O'Malley \& Chamot, 1990). Four articles involved this strategy. For example, learners watched movies or series, listened to songs over and over again for improving speaking skills (Lai et al., 2018; Ma, 2017; Sockett \& Toffoli, 2012), and reviewed previously learned words through dictionary apps (Steel, 2012; Zou \& Yan, 2014). Note-taking 


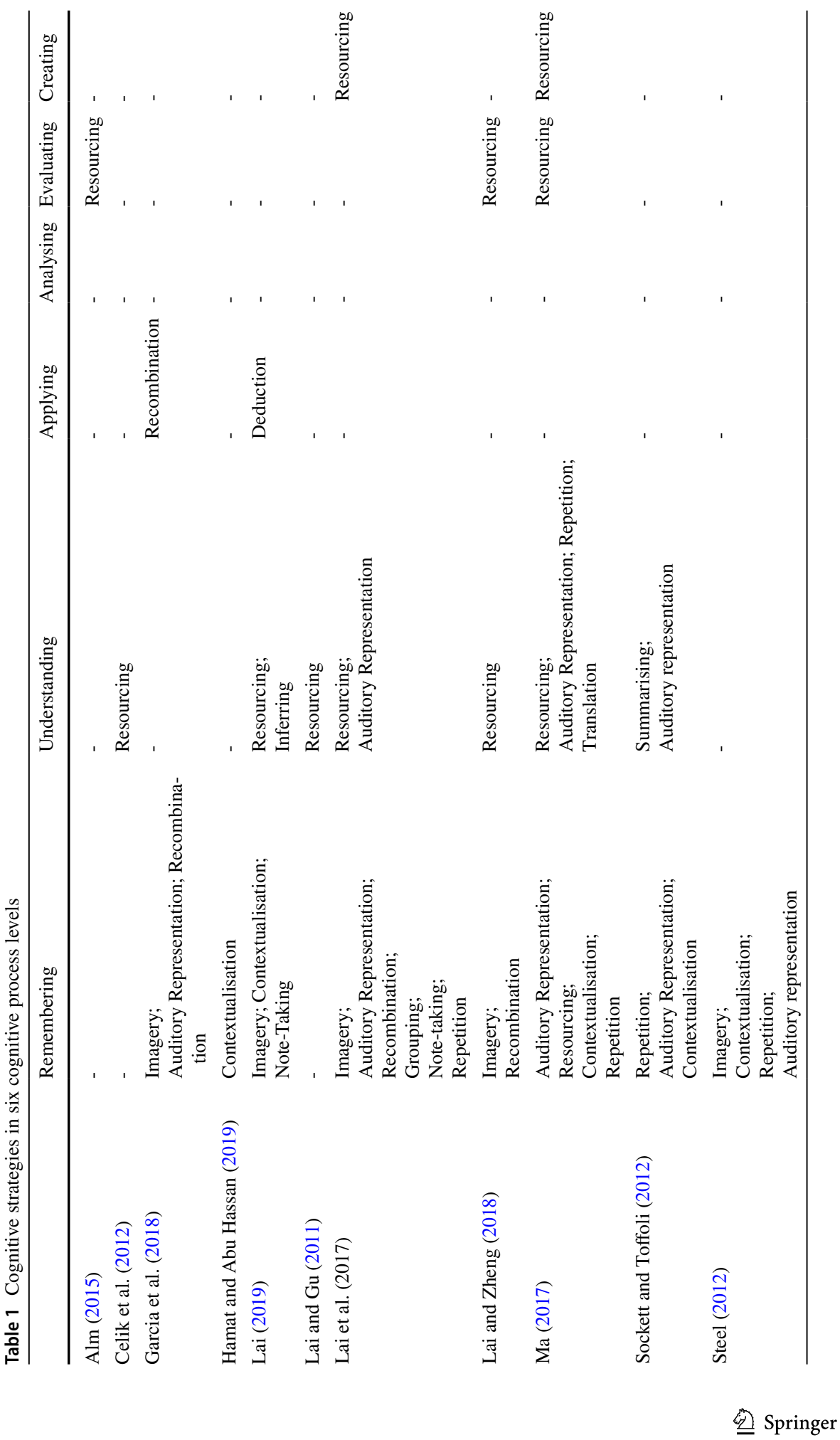




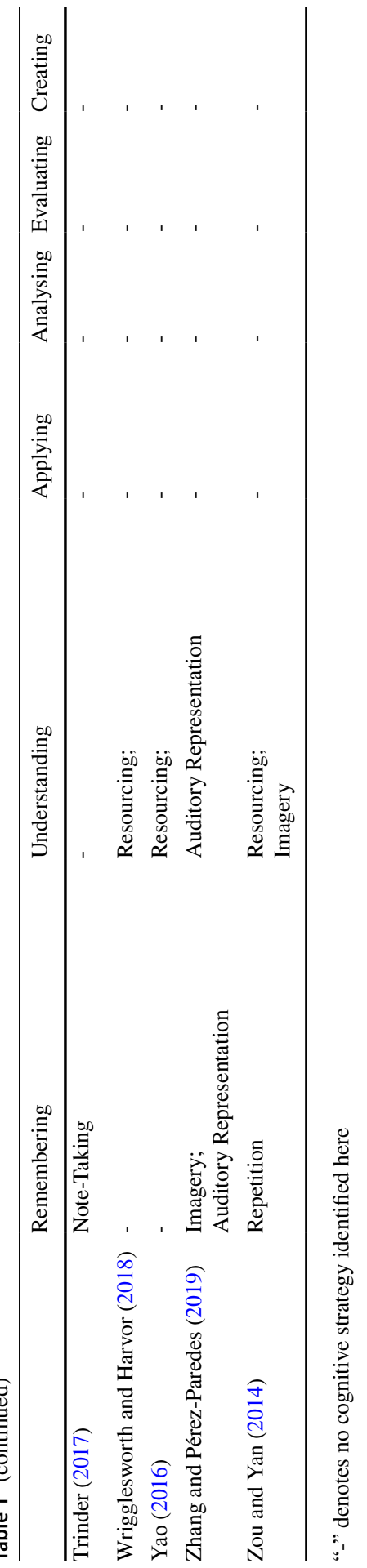

第 Springer 
means "writing down key words and concepts in abbreviated verbal, graphic, or numerical form" (O'Malley \& Chamot, 1990, p.126). Three articles mentioned this strategy when interacting with vocabulary instruction on Facebook (Lai, 2019), listening to English songs (Lai et al., 2018) and watching films (Trinder, 2017), so as to better memorise new words and expressions. Recombination means combining known knowledge in a new way to formulate meaningful sentences or language expressions (O’Malley \& Chamot, 1990). Three articles included using recombination for grammar learning through quizzes to combine known elements with the newly learned (García Botero et al., 2019; Lai \& Zheng, 2018; Lai et al., 2018). Grouping means making classifications of words, phrases, or sentences based on their attributes or meaning, and resourcing means understanding or reciting language elements by utilizing reference books, encyclopedias, websites, dictionaries, etc. (O'Malley \& Chamot, 1990). These two strategies were each only mentioned in one article. Lai et al. (Lai et al., 2018) showed that learners grouped the new words into customised lists saved in online dictionaries for vocabulary learning. Ma (2017) reported that learners knew and kept updated information regarding cultural practices and lifestyles by reading news from Yahoo US or UK (Resourcing).

Seven kinds of strategies were identified at the understanding level. Resourcing was the most commonly identified strategy, with nine articles mentioning it. Dictionaries, translating tools, search engines, and news were examined as the resourcing tools for learners to check word meaning, understand word usage and appreciate target culture (e.g., Celik et al., 2012; Wrigglesworth \& Harvor, 2018; Yao, 2016). Auditory representation is used by learners to practice and improve listening skills via listening to BBC Radio (Zhang \& Pérez-Paredes, 2019), television series (Sockett \& Toffoli, 2012), English songs and articles (Ma, 2017) and podcasts (Lai et al., 2018). Imagery, translation, and repetition were identified in one article. Some learners used Youdao Dictionary app to learn foreign languages, which provides imaginative descriptions that include pictures to help understand terms and abstract words (Imagery) (Zou \& Yan, 2014). Translation refers to the use of the native language as a basis to understand and/or produce the foreign language (O’Malley \& Chamot, 1990). Ma (2017) reported that learners first read English-version news on the BBC and then read Chineseversion news on Yahoo Hong Kong (Translation). They also read news repetitively and habitually to enhance their reading skills (Repetition) to improve reading skills. Inferencing and summarising were identified in one article. Inferencing is using the known information to infer the meaning of new elements, predict results, or complete the tasks (O'Malley \& Chamot, 1990). Lai (2019) showed that learners used this strategy to guess word meanings and infer a film's meaning from character actions and facial expressions when listening to songs and watching movies. Summarising refers to summing up the gained information in a written or mental way (O'Malley \& Chamot, 1990). Sockett and Toffoli (2012) reported that learners summarised the meanings, or at least the songs' subject, when listening.

Two kinds of strategies were identified at the applying level. One is deduction, which means applying rules to comprehend or create language output (O'Malley \& Chamot, 1990). This was reported by Lai (2019), who showed that learners applied correct grammar in order to interact with friends on WhatsApp. Another 
is recombination, which learners employed to apply what they learned in writing and listening exercises to construct new sentences in Duolingo (García Botero et al., 2019).

No strategies were identified at the analysing level, and resourcing was the only strategy examined at the evaluating and creating levels. Three articles identified resourcing strategy at the evaluating level. Two (Lai \& Zheng, 2018; Ma, 2017) mentioned that learners used dictionary apps to ensure the correct collocations in essays, and another (Alm, 2015) described using the google search engine to testthrough counting the number of hits-whether the words, phrases and sentences were accurate. In the creating level, Lai et al. (2018) and Ma (2017) indicated that some learners used dictionary apps to help write sentences or essays (Resourcing).

In summary, Table 1 shows that 16 out of 20 articles reported learners employing cognitive strategies, with more strategies at the remembering and understanding levels than at applying, analysing, evaluating and creating levels. This indicates that language learners mainly conduct more low-order learning strategies than highorder learning strategies. Table 2 indicates 12 strategies identified in the cognitive learning processes. The strategies which are identified most are resourcing and auditory representation, which are low-level strategies.

\subsection{Metacognitive strategies}

Metacognitive strategies concern the learning process and include planning for learning goals, monitoring learning tasks, and evaluating learning outcomes, such as self-monitoring, self-management, selective attention, advance organisers, directed attention, and self-evaluation (O’Malley \& Chamot, 1990). These metacognitive strategies are proved beneficial in learning success (Nückles et al., 2020). Their monitoring and controlling role in cognition means that metacognitive strategies

Table 2 Number of reviewed articles involving in learning strategies in six cognitive categories

\begin{tabular}{lllllll}
\hline Strategies & Remembering & $\begin{array}{l}\text { Under- } \\
\text { standing }\end{array}$ & Applying & Analysing & Evaluating & Creating \\
\hline Resourcing & 1 & 9 & - & - & 3 & 2 \\
Auditory representation & 6 & 4 & - & - & - & - \\
Imagery & 6 & 1 & - & - & - & - \\
Repetition & 4 & 1 & - & - & - & - \\
Contextualisation & 5 & - & - & - & - & - \\
Note taking & 3 & - & - & - & - & - \\
Recombination & 3 & - & 1 & - & - & - \\
Grouping & 1 & - & - & - & - & - \\
Inferring & - & 1 & - & - & - & - \\
Deduction & - & - & 1 & - & - & - \\
Summarising & - & 1 & - & - & - & - \\
Translation & - & 1 & - & - & - & - \\
\hline
\end{tabular}

“-" denotes no article involving in the learning strategies here 
are viewed as deep-processing and higher-order strategies (Martínez-Fernández $\&$ Vermunt, 2015). The cyclical self-regulatory phases contain the forethought, performance and self-reflection phase (Zimmerman, 2000), which is employed to categorize metacognitive strategies.

Four kinds of strategies were examined in the forethought phase: resource management, organisational planning, environment management and advance organisation. Resource management refers to seeking, arranging, or adjusting resources for learning. In the reviewed studies, this strategy was identified when learners were creating authentic learning opportunities (e.g., Celik et al., 2012; Lai, 2019; Lai \& Gu, 2011; Zhang \& Pérez-Paredes, 2019), preparing learning resources such as making personalised vocabulary lists in order to learn new words and facilitate essay writing in later phases (Lai et al., 2018; Ma, 2017), acquiring more useful materials after subscribing to bloggers who teach foreign languages (Zou \& Yan, 2014), and selecting the appropriate learning materials based on the betterknown Q\&A online forums, such as the Zhihu and Douban apps in China (Zhang \& Pérez-Paredes, 2019). Learners also downloaded mobile apps in advance for language learning (Steel, 2012). Organisational planning means generating plans for language learning tasks (O’Malley \& Chamot, 1990). For example, learners set up learning plans by themselves (Celik et al., 2012) or with the help of mobile apps (Ma, 2017; Steel, 2012; Zhang \& Pérez-Paredes, 2019). Environment management is used to set up and arrange a learning environment to make learning easier. Some learners set up environments by changing the language settings of mobile devices or applications into the target language (Alm, 2015; Chen, 2013). O'Malley and Chamot (1990) define advance organisation as "previewing the main ideas and concepts of the material to be learned, often by skimming the text for the organising principle" (p.119). In the current review, however, advance organisation refers to previewing what will be learned. It was only mentioned in one article, which reported that participants used technology to taste the language to be learned, and generate a specific plan (Lai \& Gu, 2011).

Eight kinds of strategies were found in the performance phase, the second phase of the cyclical self-regulatory phases, including comprehension monitoring, production monitoring, time management, selective attention, directed attention, resource management, effort management, and problem identification. Monitoring encompassed comprehension monitoring (checking whether learners understand) (Lai, 2019) and production monitoring (checking whether learners' language output is correct) (Lai \& Zheng, 2018; Lai et al., 2018). Time management refers to adjusting the time spent on specific tasks in order to get better results, such as extending the study hours based on study pace (Celik et al., 2012; Lai \& Gu, 2011). Selective attention means knowing how to focus on specific aspects of language learning before executing tasks (O'Malley \& Chamot, 1990). Lai (2019) reported that learners paid particular attention to using correct grammar when they applied the grammar knowledge learnt to daily interaction with friends. Sockett and Toffoli (2012) also showed that learners paid much more attention to dialogue for the purpose of learning sentence structure when watching films. Directed attention means doing or setting something beforehand to remind learning tasks (O'Malley \& Chamot, 1990). Learners sometimes reminded themselves to learn by keeping memory bars 
of vocabulary apps high (García Botero et al., 2019) and displaying study reminder popups in the English Liulishuo app (Zhang \& Pérez-Paredes, 2019). Resource management or effort management means adjusting learning resources or efforts needed in learning process. In the study by Celik et al. (2012), learners increased learning resources when they needed more, while Zhang and Pérez-Paredes (2019) showed learners made more efforts when they saw posts about the achievements of friends or classmates on vocabulary learning apps. Problem identification is identifying the problems which should be solved in tasks, or the parts that hinder understanding and completing tasks (O'Malley \& Chamot, 1990), and was adopted to identify comprehension problems after repeatedly listening to English songs (Sockett \& Toffoli, 2012).

The only learning strategy in the self-reflection phase is self-evaluation, which refers to "checking the outcomes of one's own language learning against a standard after it has been completed" (O'Malley \& Chamot, 1990, p.119). Lai and Gu (2011) and Zhang and Pérez-Paredes (2019) showed that learners assessed their language proficiency through Facebook, email and language learning apps like Liulishuo to see if they understood things well. Lai and Zheng (2018), Ma (2017) and Steel (2012) reported that learners assessed how much they knew about vocabulary and grammar through testing apps or websites.

In summary, 13 out of 20 reviewed articles are associated with metacognitive strategies in self-directed language learning. Table 3 shows that the number of reviewed articles involving the forethought phase is the most, followed by that in the performance phase and the self-reflection phase, and only two articles involve using metacognitive strategies in all three phases.

From these reviewed studies, we found that self-directed learners managed different aspects of their own learning process, such as environment, resources, time and effort. O'Malley and Chamot (1990), however, only reported a general self-management strategy. In order to show how learners manage their learning process in more detail, we divided the self-management strategy into four subcategories, including environment management, resource management, time management and effort management.

\subsection{Affective strategies}

Similar to cognitive and metacognitive strategies, affective strategies have an essential role in language learning, especially in independent settings (Hurd, 2008). These are understood as managing the emotions that affect the learning involvement (O'Malley \& Chamot, 1990). The use of these strategies assists learners in managing their feelings and attitude towards learning (Chou, 2004) to generate self-motivation and maintain interest and attention during a task, and finally to increase engagement and persistence and cultivate independent learning abilities (Fatemeh \& Fereidoon, 2016). Self-motivation, self-reinforcement, self-encouragement and self-talk belong to this type of strategy (O'Malley \& Chamot, 1990). Among the reviewed articles, only self-motivation strategy was identified, which refers to driving learners to keep going by reminding themselves of the benefits of self-directed learning or mastering 


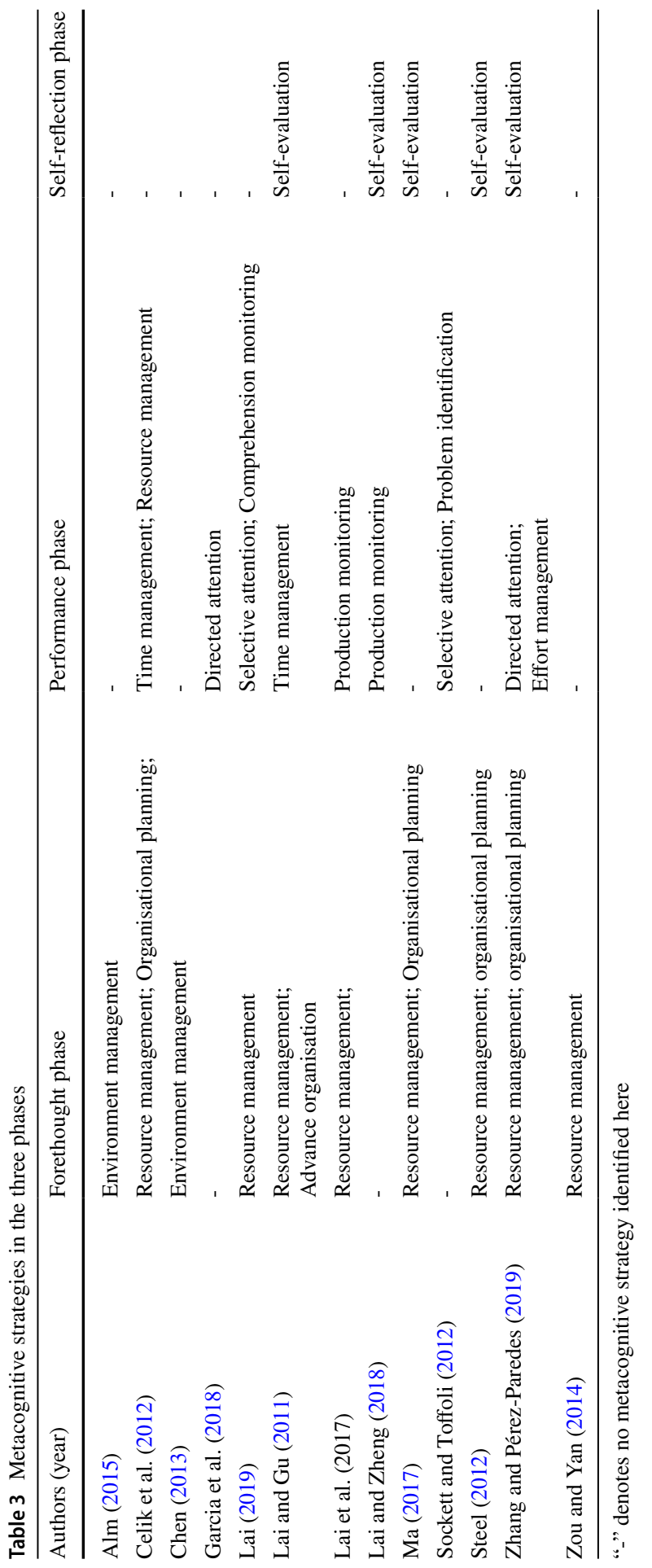


new languages (O’Malley \& Chamot, 1990). Two studies (Celik et al., 2012; Lai $\& \mathrm{Gu}, 2011)$ mentioned that learners used technology to decrease boredom and increase the enjoyment of learning tasks, which effectively maintained their interest and enthusiasm in learning and motivated them to persevere and commit to their learning goals.

\subsection{Social strategies}

Social interaction is essential for language learning since it provides authentic social contexts for language use and practice (Derakhshan \& Hasanabbasi, 2015). Not all social interactions have a positive effect on foreign language acquisition, however (Mushtaq \& Benraghda, 2018; Raut \& Patil, 2016). Social strategies are needed in order to benefit from the possibilities that social interaction offers. These strategies include cooperation and questioning for clarification (O'Malley \& Chamot, 1990), and help-receiving. Cooperation was the most frequently reported strategy, with 12 articles, which means learning with others to update information, check learning outcomes, or get feedback on learning performance (O’Malley \& Chamot, 1990). Learners used social media like WhatsApp, MSN, Facebook, MySpace, Skype, Twitter and WeChat to practice foreign languages with friends, anonymous native speakers and classmates (Chen, 2013; Kuznetsova \& Soomro, 2019; Lai, 2019; Wrigglesworth \& Harvor, 2018; Yao, 2016), and to sometimes remind each other about the mistakes they were making (Lai, 2019). Questioning for clarification is also reported, which refers to "eliciting additional explanation, rephrasing, examples, or verification from a teacher or peer" (O’Malley \& Chamot, 1990, p.120). Zou and Yan (2014) and Ma (2017) showed that participants adopted this strategy through discussion forums or social networking tools. Help-receiving is a strategy which involves other agents, such as teachers and friends, actively offering support to learners. Teachers, brothers, and friends were reported as providing help, including resource recommendation and strategy sharing in the self-directed language process (e.g., Lai et al., 2016; Yao, 2016).

Fourteen out of 20 of the reviewed articles reported social strategies used in the self-directed language learning process. Self-directed learners are also usually recommended useful learning materials and effective learning tips by teachers, peers or friends to enhance their learning. O'Malley and Chamot (1990), however, did not report a strategy about this. In order to explain this support from others, we add a new strategy, called help-receiving, to show this kind of activity.

\section{Discussion}

This review examined the learning strategies employed by university students in the self-directed language learning process using mobile technology. Only 20 articles were included in this review, as many other studies focused on teacher-initiated self-regulated learning. In order to make informed educational decisions about different aspects of language learning, this review has investigated the cognitive, 
metacognitive, affective and social strategies that learners use in their self-directed learning process. These strategies range from low-level cognitive processes, such as remembering and understanding, to processes at a high level of cognitive complexity, such as planning, monitoring, reflecting, evaluating and creating. It was clear from the literature review that the use of cognitive strategies was more commonly reported in relation to low-level cognitive processes, remembering and understanding, than in high-level cognitive processes, applying, analysing, evaluating and creating. The two most frequently used strategies, resourcing and auditory representation, are low-level cognitive strategies. Although these low-level strategies are appropriate and work well when learning for a short-term purpose or when learning facts and details (Setiyadi, 2001), in order to improve overall language performance, they should be complemented with the use of high-order strategies throughout the learning process (Aharony, 2006; Setiyadi, 2001; Yot-Domínguez \& Marcelo, 2017). Therefore, more research is necessary to examine the higher-order strategies. More of the reviewed articles examined the metacognitive strategies associated with the forethought phase and performance phase than those related to the selfreflection phase, and only a few articles reported on all three metacognitive phases. Only one affective strategy, self-motivation, was reported in two articles, and three kinds of social strategies were examined in the reviewed articles. Future studies are encouraged to focus on social and affective strategies as they are related to effective learning in language learning (Chamot, 2005; Zeynali, 2016).

\subsection{Self-directed language learning and self-regulatory phases}

Only two articles reported on all three self-regulatory phases. Zimmerman (2000) stated that self-regulation is cyclical, from the forethought phase to the performance phase to the self-reflection phase, and that the three phases are all essential for selfdirected learners. The forethought phase helps learners strategically prepare for upcoming tasks, the performance phase is important as learners make adjustments to their learning promptly according to the feedback from monitoring and evaluating, and self-reflection influences the forethought processes of a learner's subsequent learning actions in fulfilling the self-regulatory cycle (Zimmerman, 2000, 2008). To our best knowledge, however, few empirical studies examined whether participating in all three phases would lead to better language performance. We thus encourage more empirical research on the impact of using a complete cycle of self-regulatory processes.

\subsection{Affective strategies}

This review study showed that affective strategies received little attention in research regarding self-directed language learning using mobile technology since only two reviewed articles reported one similar strategy, self-motivation. One possible reason is that researchers may not pay much attention to affective strategies in the mobile environment because using mobile technology itself has played a highly motivating role in the process due to its appealing characteristics (Jones et al., 2006). However, 
although using mobile technology can motivate self-directed learners to learn, it is temporary, and learners are easily distracted, interrupted (Crescente \& Lee, 2011; Kacetl \& Klímová, 2019; Wolters \& Rosenthal, 2000). There is thus still a need to investigate affective strategies as they can boost a learner's continuance motivation in the mobile learning environment and have a great effect on the success of language learning (Anderson, 1991). Addressing other emotional feelings is also crucial. Nasri et al. (2015) revealed that some language learners were susceptible to negative emotions like diffidence, anxiety and trauma. Affective strategies, such as self-encouragement and self-reinforcement, may assist them in managing these negative emotions, further achieving successful learning (Nasri et al., 2015). Researchers and self-directed learners are therefore recommended to focus more on affective strategies in the future as well (Vermunt \& Donche, 2017).

\subsection{Limited knowledge about strategies for language learning}

Several reviewed articles showed that learners had limited knowledge about strategy use (Lai et al., 2016; Zhang \& Pérez-Paredes, 2019) and technology use (Chen, 2013; Lai \& Gu, 2011; Lai \& Zheng, 2018) in the self-directed learning process using mobile technology. Lai et al. (2016) and Zhang and Pérez-Paredes (2019) stated that learners had difficulties in locating and selecting useful, appropriate and trustworthy resources and effectively using them for language learning. Chen (2013) and Lai and Zheng (2018) showed that learners lacked the necessary knowledge and experience to utilise mobile devices for establishing social connections and authenticity. In order to address these issues, teachers are encouraged to facilitate and support learners in technology-enhanced language learning environments, which is in line with the review study by Zhou and Wei (2018). Lai (2015) reported that teachers could provide "affection support, capacity support and behaviour support", which strengthens a learner's awareness of the usefulness of technological resources, improves their abilities to locate and utilize these resources for learning, and scaffolds them experimenting with resources in out-of-class learning. However, teachers saw themselves a minimal role as they overestimated students' abilities and worried about their limited knowledge to offer assistance (Lai et al., 2016). This finding therefore highlighted the significance of increasing teacher awareness that they can play various roles in enhancing student knowledge of, and skills in, using mobile technology in the out-of-class self-directed learning. There is also a call for more research on how to enable teachers to exert their influence on fostering students' self-directed learning using technology.

\subsection{Importance of social interaction}

Although this study did not focus on technology use, several reviewed studies (Lai \& Gu, 2011; Lai \& Zheng, 2018; Lai et al., 2018) showed that students seldom used technology for social interaction and were sceptical about it because they were not confident about their proficiency levels during online interactions, were afraid of getting incorrect feedback, and lacked an overlap between online friends and 
possible language partners (Lai \& Gu, 2011; Lai \& Zheng, 2018; Lai et al., 2018). Nevertheless, social interaction is essential since self-directed language learning is seen as a social activity (Alvi \& Gillies, 2015; Heil et al., 2016). Mobile technology can also facilitate social interaction in the language learning process, as mobile technology offers language learners the possibility of sharing files, data or simple messages, and authentic opportunities to use what they have learned practically through cooperating and communicating with their peers, native speakers or teachers (Troussas et al., 2014). These affordances are beneficial for long-term language practices, further motivating learning and enhancing language performance (Kukulska-Hulme \& Viberg, 2018). In order to maximise the potential of mobile technology for social interaction in language learning, future studies are advised to systematically examine the factors that affect the use and effects of mobile technology for social interaction in learning, and explore effective educational interventions to promote the use of technology by self-directed learners for social interaction in self-directed language learning.

\subsection{Limitations and future directions}

Many reviewed studies lack information about the participants' proficiency levels. Only 11 out of 20 studies reported the proficiency levels of the participants. Most focused on beginners or intermediates, and only one focused on advanced students. From earlier research, we knew that students at different proficiency levels used strategies differently (Green \& Oxford, 1995; Hong-Nam \& Leavell, 2006; Park, 1997; Wharton, 2000). We thus recommend that future studies provide more information about participants' proficiency levels in their studies, as this information may enable researchers to do further research in related fields and offer more evidence to educators in order to plan efficient scaffolding for self-directed learners. More attention should also be paid to the less-explored learner populations to see whether there are more varieties in their strategy patterns and skills, and their targeted language areas (Steel, 2012).

\subsection{Practical implications}

The research findings reveal cognitive, metacognitive, social and affective strategies that self-directed learners use in their learning process. These findings have a number of implications for empowering self-directed learners, educators/teachers, and software agents.

It is recommended that self-directed learners prepare themselves before starting selfdirected learning. Self-directed learning seems to be more appropriate for intermediate and advanced language learners than for beginners (Sakai \& Takagi, 2009; Ünal et al., 2017). Language learners can conduct self-directed learning only when they reach a basic proficiency level. Good language learners usually use a larger number and wider range of strategies in combination (Chamot et al., 1996; Nasri et al., 2015; Oxford, 1999). Some language learners, however, used just one or two types of strategies in their self-directed learning process (e.g., Trinder, 2017; Wrigglesworth \& Harvor, 2018). In 
order to become better self-directed language learners, it is necessary for learners to reach a basic proficiency level and integrate more appropriate strategies into their learning processes, especially deep-level cognitive strategies and affective strategies.

From the perspective of language educators/teachers, guidance should be provided for learners in order to facilitate their autonomous learning effectively. Given the limited knowledge that self-directed learners have of strategy use and technology use, teachers could recommend a wide range of technological resources, share metacognitive and cognitive strategies for effective use of the resources, and encourage students to actively use technology to support their language learning (Zhang \& Pérez-Paredes, 2019). In order to better advise and support self-directed learners, teachers should also be supported in raising their awareness of the multiple roles they could have, such as providing affective support, capacity support and behaviour support, and equipping themselves with the necessary knowledge and skills to foster the self-directed learning of students.

For software developers, more adaptive learning features should be incorporated into software applications to help formulate users' personalised learning experiences based on their learning styles, background and technological access, which could offer better learning experiences for self-directed learners. Our findings show that independent learners seldom participate in high-level cognitive processes and often could not get useful feedback when interacting with others. These issues may be addressed by software developers by incorporating adaptive features into software applications. Software applications with adaptive features could make "intelligent" decisions based on users' performance (Heil et al., 2016), such as designing high cognitive activities if learners master the low-level skills, and providing correct and personalised feedback based on the mistakes that users make during social interactions. More work is needed to track the effectiveness of these adaptive features. Based on the empirical results, it may be appropriate to make suggestions about the software design outcome.

\section{Concluding remarks}

Along with the increasing necessity of self-directed learning using mobile technology, there is a need to understand the self-directed learning process. This systematic scoping review examined 20 empirical studies to determine the learning strategies that selfdirected learners used in their learning process. The main conclusion of this review was that self-directed learners used cognitive, metacognitive, social and affective strategies in their learning process, ranging from the simplest to a high level of intentionality and cognitive complexity. More precisely, low-cognitive strategies appeared to be more commonly reported than high-cognitive strategies. The use of metacognitive strategies was more closely associated with the forethought phase and performance phase than with the self-reflection phase, yet only a few articles reported all three metacognitive phases. And, three kinds of social strategies were examined, and only one affective strategy was reported. We call for more studies to gain insight into affective strategies and high-order cognitive process in self-directed language learning. In order to further exploit selfdirected language learning using mobile technology, future research is advised to focus on the support of other agents for self-directed learners and the relationships between the proficiency levels of self-directed language learners and their strategy use. 


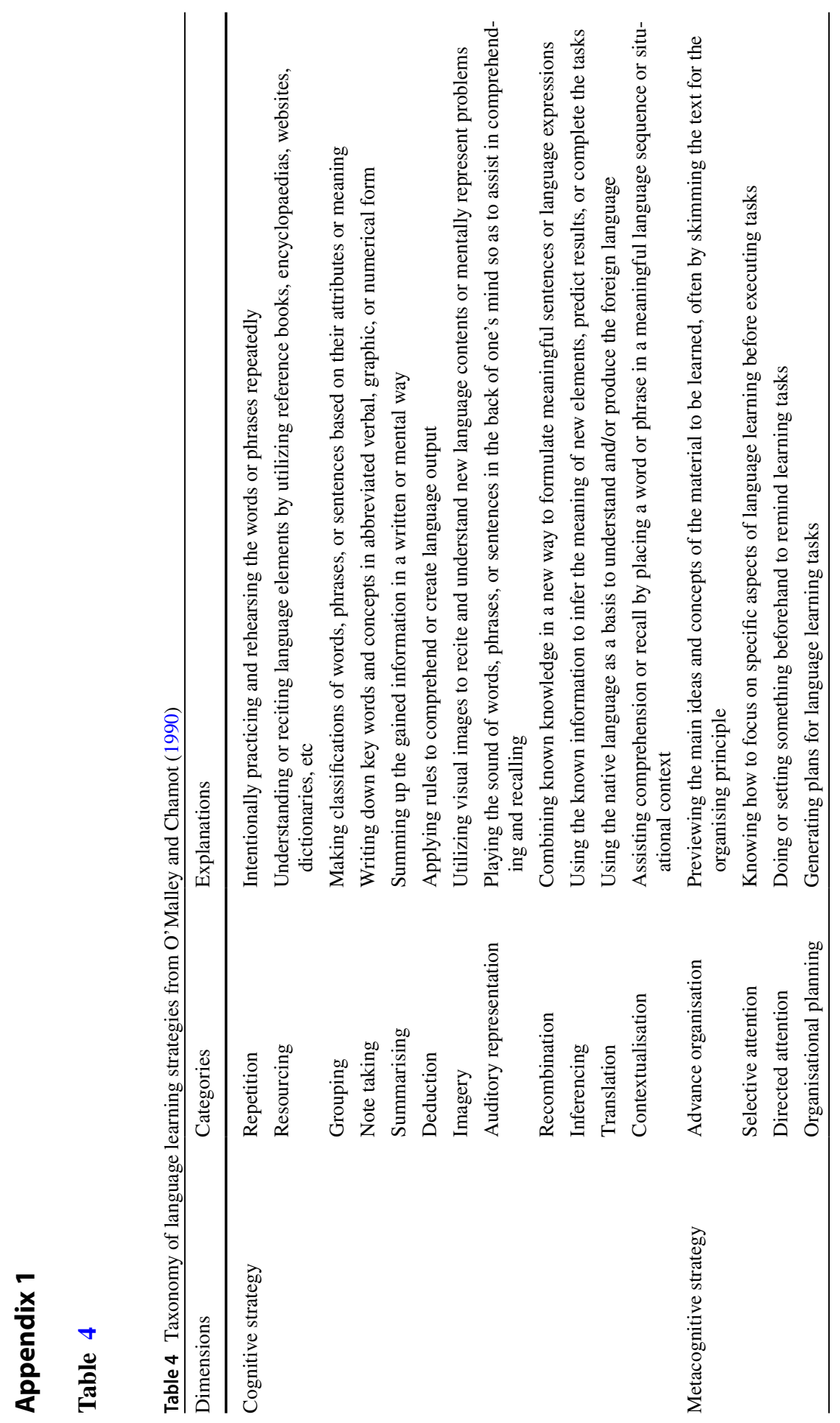




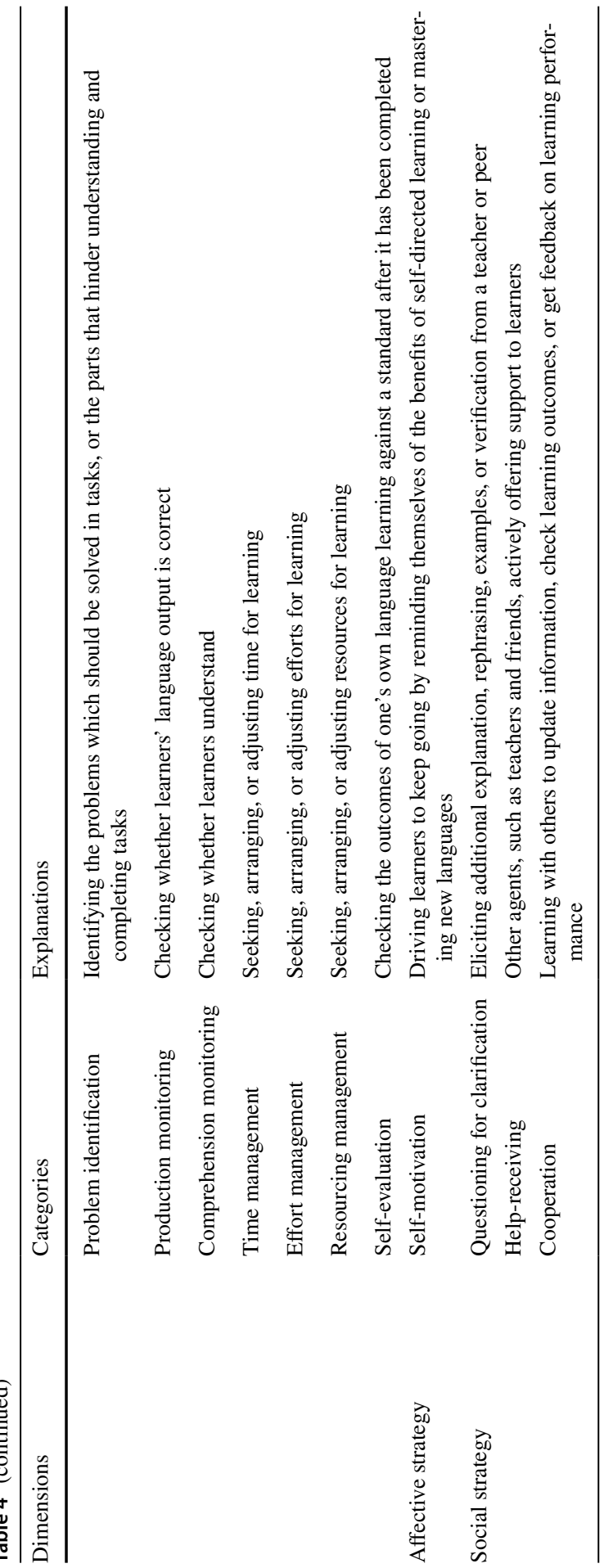




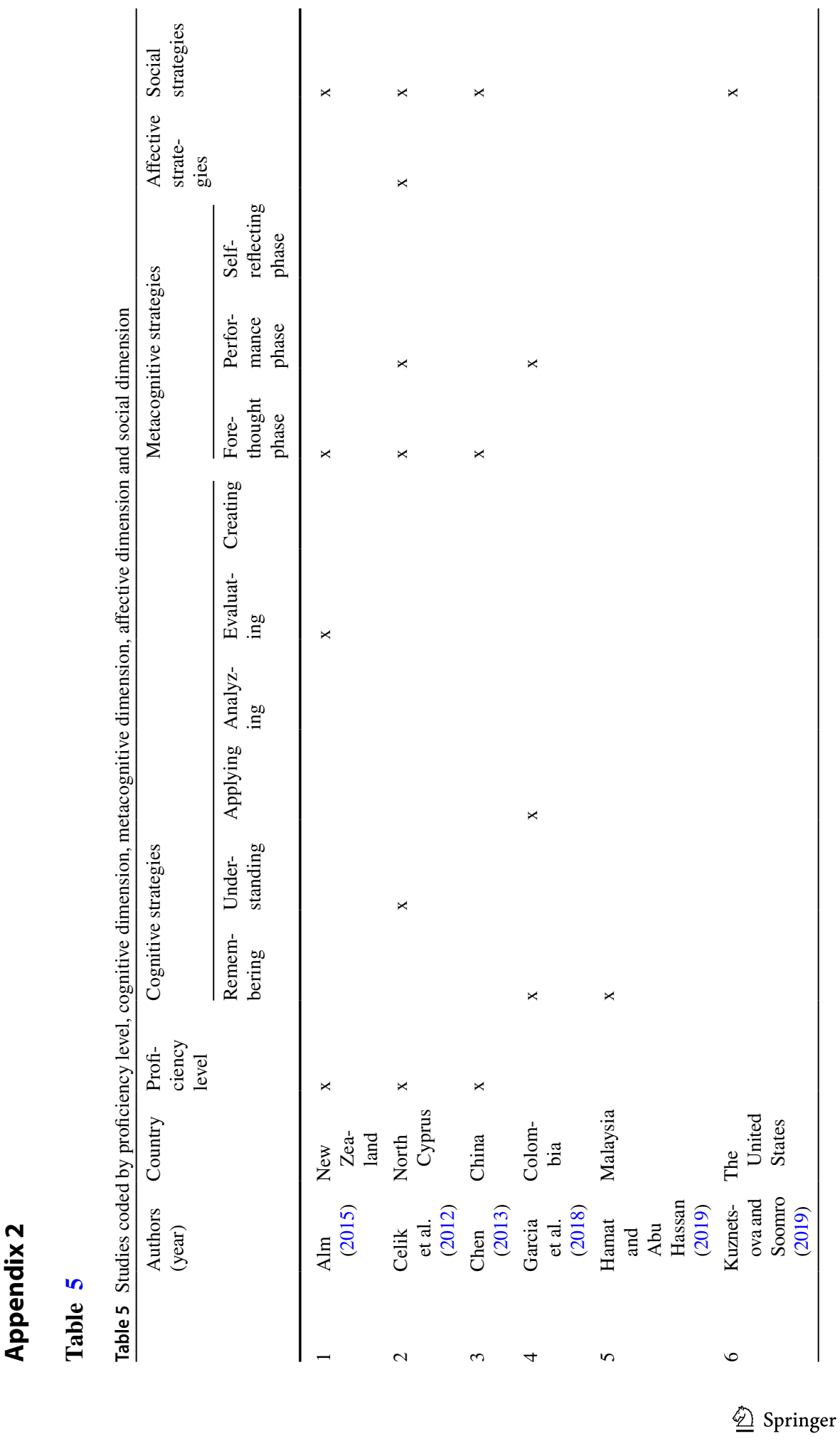




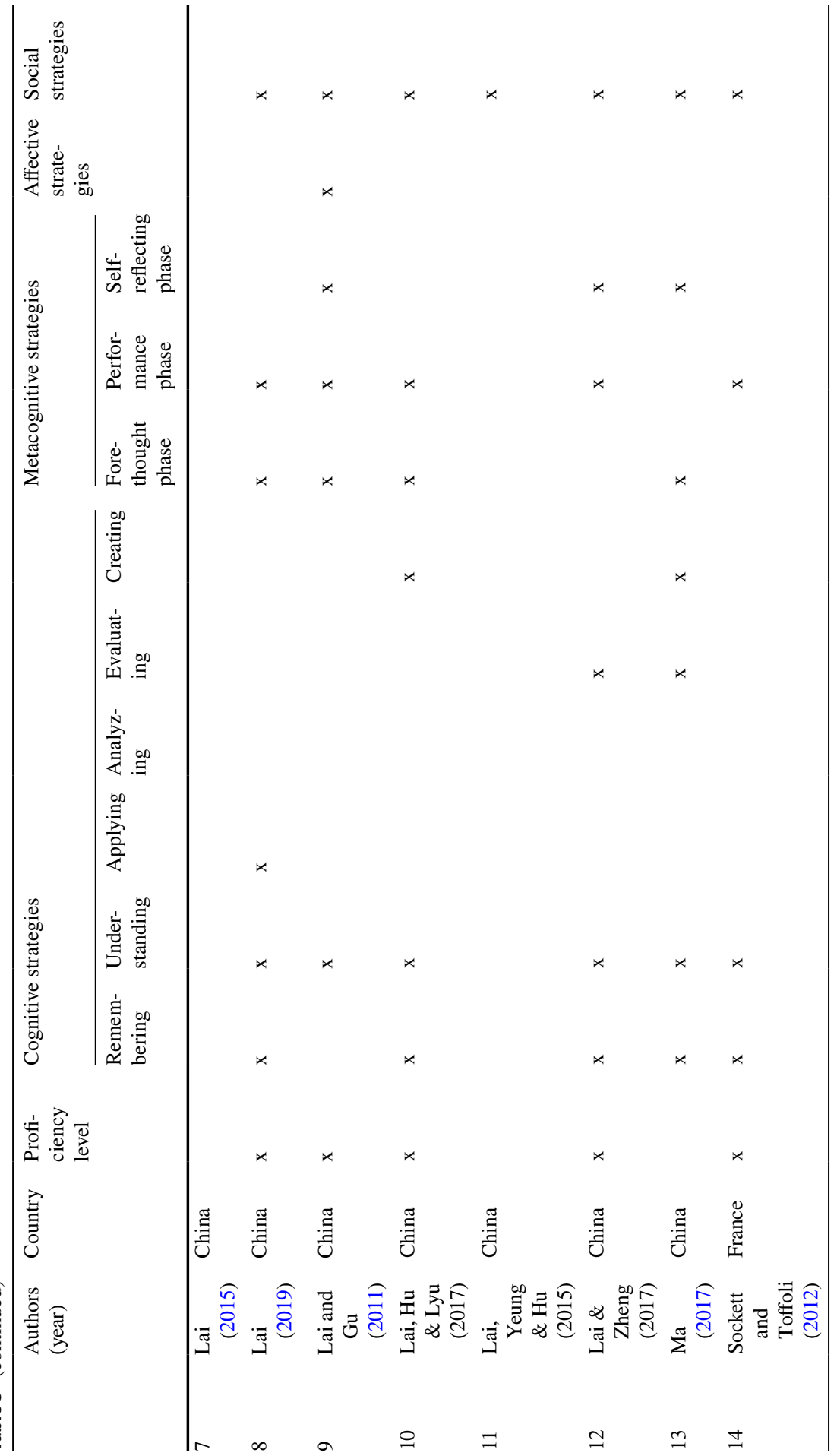


Education and Information Technologies (2022) 27:7749-7780

7773

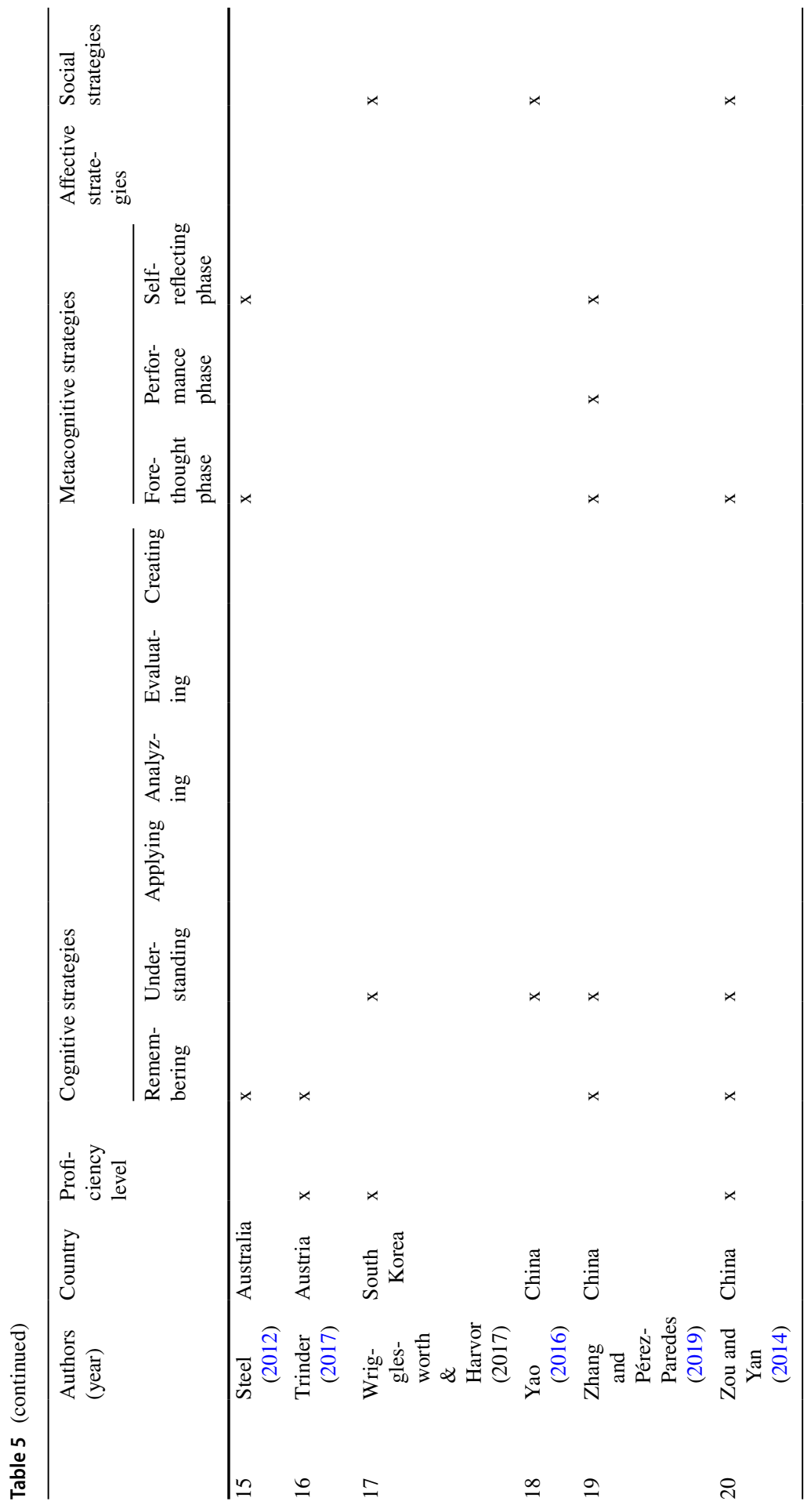

Springer 


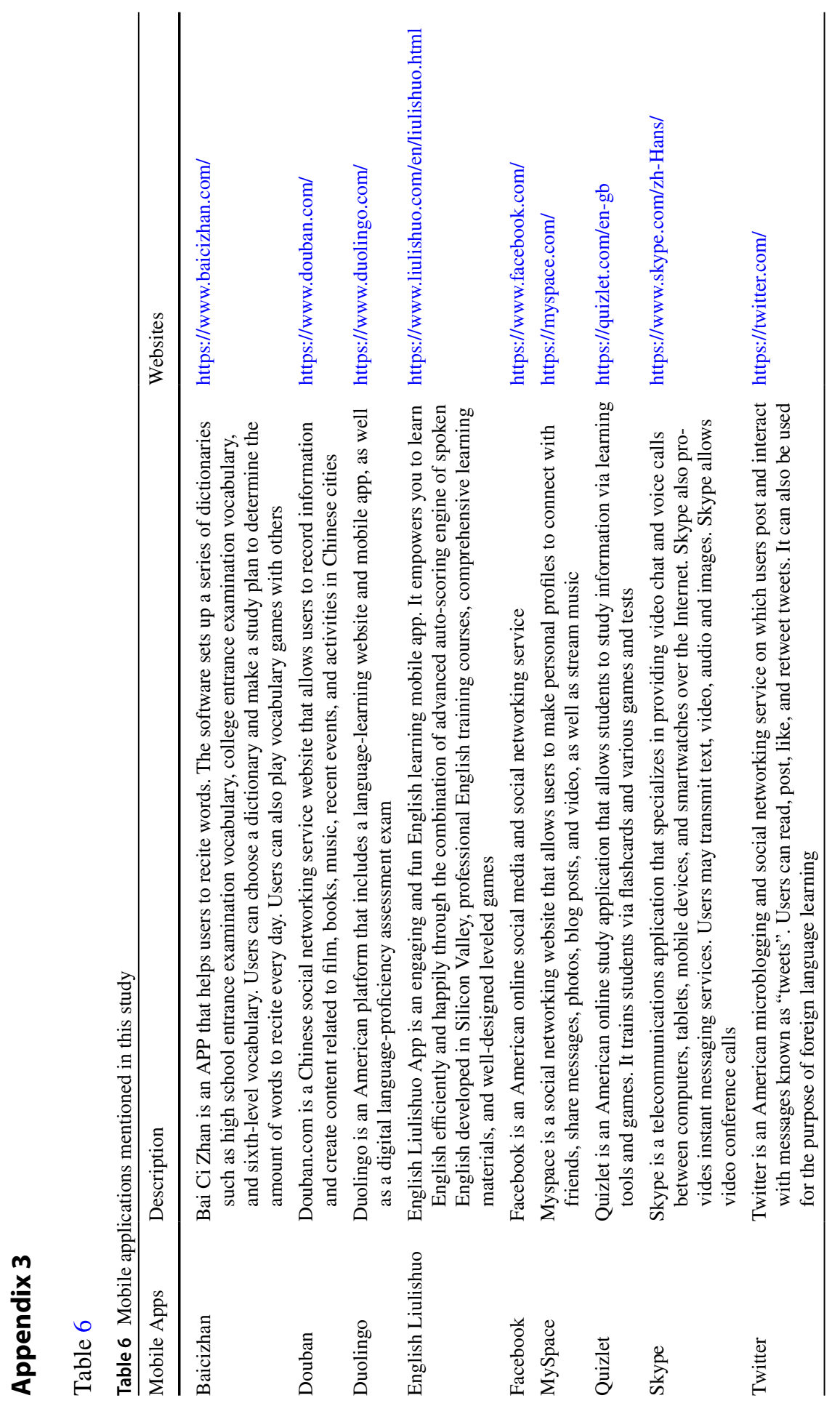




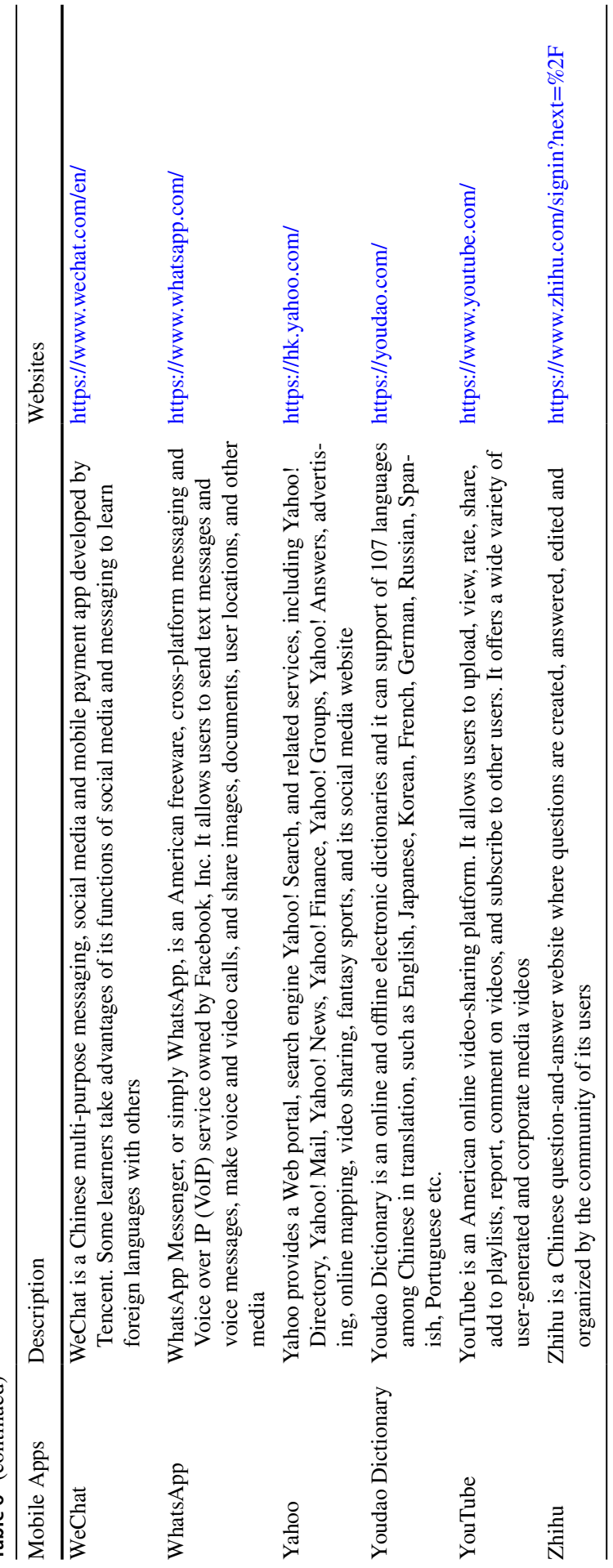


Acknowledgements This work was supported by the China Scholarship Council [grant number 202007720024]. Additionally, I would like to give special thanks to my parents, Mr. Anming Lai and Mrs. Wenli Xu, and my husband, Dr. Nan Pu for their spiritual support and invaluable love over these years.

\section{Declarations}

\section{Conflict of interest None.}

Open Access This article is licensed under a Creative Commons Attribution 4.0 International License, which permits use, sharing, adaptation, distribution and reproduction in any medium or format, as long as you give appropriate credit to the original author(s) and the source, provide a link to the Creative Commons licence, and indicate if changes were made. The images or other third party material in this article are included in the article's Creative Commons licence, unless indicated otherwise in a credit line to the material. If material is not included in the article's Creative Commons licence and your intended use is not permitted by statutory regulation or exceeds the permitted use, you will need to obtain permission directly from the copyright holder. To view a copy of this licence, visit http://creativecommons.org/licen ses/by/4.0/.

\section{References}

\section{Note: Studies marked with an asterisk were included in the review analysis.}

Aharony, N. (2006). The use of deep and surface learning strategies among students learning English as a foreign language in an Internet environment. British Journal of Educational Psychology, 76(4), 851-866. https://doi.org/10.1348/000709905X79158

Alm, A. (2015). Facebook for informal language learning: Perspectives from tertiary language students. The EuroCALL Review, 23(2), 3. https://doi.org/10.4995/eurocall.2015.4665

Alvi, E., \& Gillies, R. M. (2015). Social interactions that support students' self-regulated learning: A case study of one teacher's experiences. International Journal of Educational Research, 72, 14-25. https://doi.org/10.1016/j.ijer.2015.04.008

Anderson, L. W., Krathwohl, D. R., \& Airasian, P. W. (2001). A taxonomy for learning, teaching, and assessing : A revision of Bloom's taxonomy of educational objectives. Longman.

Anderson, N. J. (1991). Individual differences in strategy use in second language reading and testing. The Modern Language Journal, 75(4), 460. https://doi.org/10.2307/329495

Anthonysamy, L., Koo, A. C., \& Hew, S. H. (2020). Self-regulated learning strategies and non-academic outcomes in higher education blended learning environments: A one decade review. Education and Information Technologies, 1-28.https://doi.org/10.1007/s10639-020-10134-2

Broadbent, J., \& Poon, W. L. (2015). Self-regulated learning strategies \& academic achievement in online higher education learning environments: A systematic review. The Internet and Higher Education, 27, 1-13. https://doi.org/10.1016/j.iheduc.2015.04.007

Celik, S., Arkin, E., \& Sabriler, D. (2012). EFL learners' use of ICT for self-regulated learning. The Journal of Language and Linguistic Studies, 8(2), 98-118. https://doi.org/10.17263/jlls.16954

Chamot, A. U. (2005). Language learning strategy instruction: Current issues and research. Annual Review of Applied Linguistics, 25, 112-130. https://doi.org/10.1017/S0267190505000061

Chamot, A. U., Barnhardt, S., El-Dinary, P., \& Robbins, J. (1996). Methods for teaching learning strategies in the foreign language classroom. In R. L. Oxford (Ed.), Language learning strategies around the world: Cross-cultural perspectives (pp. 175-187). University of Hawaii Press.

Chinnery, G. M. (2006). Going to the MALL: Mobile Assisted Language Learning. Language Learning \& Technology, 10(1), 9-16. 
Chen, C.-M., \& Li, Y.-L. (2010). Personalised context-aware ubiquitous learning system for supporting effective English vocabulary learning. Interactive Learning Environments, 18(4), 341-364. https:// doi.org/10.1080/10494820802602329

Chen, X.-B. (2013). Tablets for informal language learning: Student usage and attitudes. Language Learning \& Technology, 17(1), 20-36.

Chou, Y.-L. (2004). Promoting learners' speaking ability by socio-affective strategies. The Internet TESL Journal, 10(9).

Crescente, M. L., \& Lee, D. (2011). Critical issues of m-learning: Design models, adoption processes, and future trends. Journal of the Chinese Institute of Industrial Engineers, 28(2), 111-123. https:// doi.org/10.1080/10170669.2010.548856

Crompton, H., Burke, D., \& Lin, Y. (2019). Mobile learning and student cognition: A systematic review of PK-12 research using Bloom's Taxonomy. British Journal of Educational Technology, 50(2), 684-701. https://doi.org/10.1111/bjet.12674

Dent, A. L., \& Koenka, A. C. (2016). The relation between self-regulated learning and academic achievement across childhood and adolescence: A meta-analysis. Educational Psychology Review, 28(3), 425-474. https://doi.org/10.1007/s10648-015-9320-8

Derakhshan, A., \& Hasanabbasi, S. (2015). Social networks for language learning. Theory and Practice in Language Studies, 5(5), 1090. https://doi.org/10.17507/tpls.0505.25

Fatemeh, M., \& Fereidoon, V. (2016). The effect of explicit affective strategy training on Iranian EFL learners' oral language proficiency and anxiety reduction. Advances in Language and Literary Studies, 7(4), 197-210. https://doi.org/10.7575/aiac.alls.v.7n.4p.197

GarcíaBotero, G., Questier, F., \& Zhu, C. (2019). Self-directed language learning in a mobile-assisted, out-of-class context: Do students walk the talk? Computer Assisted Language Learning, 32(1-2), 71-97. https://doi.org/10.1080/09588221.2018.1485707

Garcia, R., Falkner, K., \& Vivian, R. (2018). Systematic literature review: Self-regulated learning strategies using e-learning tools for computer science. Computers \& Education, 123, 150-163. https://doi.org/10.1016/j.compedu.2018.05.006

Green, J. M., \& Oxford, R. (1995). A closer look at learning strategies, L2 proficiency, and gender. TESOL Quarterly, 29(2), 261. https://doi.org/10.2307/3587625

Hall, J. K. (2001). Methods for teaching foreign languages: Creating a community of learners in the classroom. Prentice Hall.

Hamat, A., \& Abu Hassan, H. (2019). Use of social media for informal language learning by Malaysian university students. 3L The Southeast Asian Journal of English Language Studies, 25(4), 68-83. https://doi.org/10.17576/3L-2019-2504-05

Heil, C. R., Wu, J. S., Lee, J. J., \& Schmidt, T. (2016). A review of mobile language learning applications: Trends, challenges, and opportunities. The EuroCALL Review, 24(2), 32. https://doi.org/10. 4995/eurocall.2016.6402

Hismanoglu, M. (2000). Language learning strategies in foreign language learning and teaching. The Internet TESL Journal, 6(8), 12.

Hong-Nam, K., \& Leavell, A. G. (2006). Language learning strategy use of ESL students in an intensive English learning context. System, 34(3), 399-415. https://doi.org/10.1016/j.system.2006.02.002

Hsiao, T.-Y., \& Oxford, R. L. (2002). Comparing theories of language learning strategies: A confirmatory factor analysis. The Modern Language Journal, 86(3), 368-383. https://doi.org/10.1111/1540-4781. 00155

Hurd, S. (2008). Affect and strategy use in independent language learning. In S. Hurd \& T. Lewis (Eds.), Language learning strategies in independent settings (pp. 218-236). Multilingual Matters.

Jansen, R. S., Van Leeuwen, A., Janssen, J., Jak, S., \& Kester, L. (2019). Self-regulated learning partially mediates the effect of self-regulated learning interventions on achievement in higher education: A meta-analysis. Educational Research Review, 28, 100292. https://doi.org/10.1016/j.edurev.2019. 100292

Jones, A., Issroff, K., Scanlon, E., Clough, G., \& Mcandrew, P. (2006). Using mobile devices for learning in informal settings: Is it motivating? IADIS International Conference Mobile Learning, (January), 251-255.

Jossberger, H., Brand-Gruwel, S., Boshuizen, H., \& van de Wiel, M. (2010). The challenge of selfdirected and self-regulated learning in vocational education: A theoretical analysis and synthesis of requirements. Journal of Vocational Education \& Training, 62(4), 415-440. https://doi.org/ $10.1080 / 13636820.2010 .523479$ 
Kacetl, J., \& Klímová, B. (2019). Use of smartphone applications in English language learning-a challenge for foreign language education. Education Sciences, 9(3), 179. https://doi.org/10.3390/ educsci9030179

Knowles, M. S. (1975). Self-directed learning : A guide for learners and teachers. The Adult Education Co.

Kramsch, C. (2014). Teaching foreign languages in an era of globalization: Introduction. The Modern Language Journal, 98(1), 296-311. https://doi.org/10.1111/j.1540-4781.2014.12057.x

Kuimova, M., Burleigh, D., Uzunboylu, H., \& Bazhenov, R. (2018). Positive effects of mobile learning on foreign language learning. TEM Journal, 7(4), 837-841. https://doi.org/10.18421/TEM74-22

Kukulska-Hulme, A., \& Viberg, O. (2018). Mobile collaborative language learning: State of the art. British Journal of Educational Technology, 49(2), 207-218. https://doi.org/10.1111/bjet.12580

Kuznetsova, N., \& Soomro, K. (2019). Students' out-of-class web 2.0 practices in foreign language learning. Journal of Education and Educational Development, 6(1), 78-94. https://doi.org/10. 22555/joeed.v6i1.2713

Lai, C. (2015). Modelling teachers' influence on learners' self-directed use of technology for language learning outside the classroom. Computers \& Education, 82, 74-83. https://doi.org/10.1016/j. compedu.2014.11.005

Lai, C. (2019). Learning beliefs and autonomous language learning with technology beyond the classroom. Language Awareness, 28(4), 291-309. https://doi.org/10.1080/09658416.2019.1675679

Lai, C., \& Gu, M. (2011). Self-regulated out-of-class language learning with technology. Computer Assisted Language Learning, 24(4), 317-335. https://doi.org/10.1080/09588221.2011.568417

Lai, C., Hu, X., \& Lyu, B. (2018). Understanding the nature of learners' out-of-class language learning experience with technology. Computer Assisted Language Learning, 31(1-2), 114-143. https://doi.org/10.1080/09588221.2017.1391293

Lai, C., Yeung, Y., \& Hu, J. (2016). University student and teacher perceptions of teacher roles in promoting autonomous language learning with technology outside the classroom. Computer Assisted Language Learning, 29(4), 703-723. https://doi.org/10.1080/09588221.2015.1016441

Lai, C., \& Zheng, D. (2018). Self-directed use of mobile devices for language learning beyond the classroom. ReCALL, 30(3), 299-318. https://doi.org/10.1017/S0958344017000258

Lai, Y., Saab, N., \& Admiraal, W. (2022). University students' use of mobile technology in selfdirected language learning: Using the integrative model of behavior prediction. Computers \& Education, 179, 104413. https://doi.org/10.1016/j.compedu.2021.104413

Lan, Y. J., Sung, Y. T., \& Chang, K. E. (2007). A mobile-device-supported peer-assisted learning system for collaborative early EFL reading. Language Learning \& Technology, 11(3), 130-151.

Lee, D., Watson, S. L., \& Watson, W. R. (2019). Systematic literature review on self-regulated learning in massive open online courses. Australasian Journal of Educational Technology, 35(1). https://doi.org/10.14742/ajet.3749

Loyens, S., Magda, J., \& Rikers, R. (2008). Self-directed learning in problem-based learning and its relationships with self-regulated learning. Educational Psychology Review, 20(4), 411-427. https://doi.org/10.1007/s10648-008-9082-7

Ma, Q. (2017). A multi-case study of university students' language-learning experience mediated by mobile technologies: A socio-cultural perspective. Computer Assisted Language Learning, 30(34), 183-203. https://doi.org/10.1080/09588221.2017.1301957

Martínez-Fernández, J. R., \& Vermunt, J. D. (2015). A cross-cultural analysis of the patterns of learning and academic performance of Spanish and Latin-American undergraduates. Studies in Higher Education, 40, 278-295. https://doi.org/10.1080/03075079.2013.823934

Merriam, S. B., \& Bierema, L. L. (2013). Adult learning: Linking theory and practice. Wiley.

Moher, D., Liberati, A., Tetzlaff, J., \& Altman, D. G. (2009). Preferred reporting items for systematic reviews and meta-analyses: The PRISMA statement. PLoS Medicine, 6(7), e1000097. https://doi. org/10.1371/journal.pmed.1000097

Mushtaq, A. J., \& Benraghda, A. (2018). The effects of social media on the undergraduate students' academic performances. Library Philosophy and Practice, 4(1).

Nasri, N. M., Yunus, M. M., \& Nazri, N. D. M. (2015). Through the lens of good language learners: What are their strategies? Advances in Language and Literary Studies, 7(1), 195-202. https://doi. org/10.7575/aiac.alls.v.7n.1p.195

Nückles, M., Roelle, J., Glogger-Frey, I., Waldeyer, J., \& Renkl, A. (2020). The self-regulation-view in writing-to-learn: Using journal writing to optimize cognitive load in self-regulated learning. Educational Psychology Review, 32(4), 1089-1126. https://doi.org/10.1007/s10648-020-09541-1 
O’Malley, J. M., \& Chamot, A. U. (1990). Learning strategies in second language acquisition. Cambridge University Press.

Oxford, R. L. (1990). Language learning strategies: What every teacher should know. Newbury House.

Oxford, R. L. (1999). Relationships between second language learning strategies and language proficiency in the context of learner autonomy and self-regulation. Revista Canaria De Estudios Ingleses, 38(1), 108-126.

Park, G. (1997). Language learning strategies and English proficiency in Korean university students. Foreign Language Annals, 30(2), 211-221. https://doi.org/10.1111/j.1944-9720.1997.tb02343.x

Qingquan, N., Chatupote, M., \& Teo, A. (2008). A deep look into learning strategy use by successful and unsuccessful students in the Chinese EFL learning context. RELC Journal, 39(3), 338-358. https:// doi.org/10.1177/0033688208096845

Raidal, S. L., \& Volet, S. E. (2008). Preclinical students' predispositions towards social forms of instruction and self-directed learning: A challenge for the development of autonomous and collaborative learners. Higher Education, 57(5), 577-596. https://doi.org/10.1046/j.13652923.2000.00753.x

Raut, V., \& Patil, P. (2016). Use of social media in education: Positive and negative impact on the students. International Journal on Recent and Innovation Trends in Computing and Communication, $4(1), 281-285$.

Richards, J. C. (2015). The changing face of language learning: Learning beyond the classroom. RELC Journal, 46(1), 5-22. https://doi.org/10.1177/0033688214561621

Rusnadi, R. (2017). Language learning strategies of ESL learners at Murray State University in improving their English language skills. LET Linguistics, Literature and English Teaching Journal, 4(1), 1-19. https://doi.org/10.18592/let.v4i1.1396

Sakai, S., \& Takagi, A. (2009). Relationship between learner autonomy and English language proficiency of Japanese learners. Journal of Asia TEFL, 6(3).

Setiyadi, A. B. (2001). Language learning strategies: Classification and pedagogical implication. TEFLIN Journal, 12(1). https://doi.org/10.15639/teflinjournal.v12i1/15-28

Sockett, G., \& Toffoli, D. (2012). Beyond learner autonomy: A dynamic systems view of the informal learning of English in virtual online communities. ReCALL, 24(2), 138-151. https://doi.org/10. $1017 /$ S0958344012000031

Steel, C. (2012). Fitting learning into life: Language students' perspectives on benefits of using mobile apps. In M. Brown, M. Hartnett, \& T. Stewart (Eds.), ascilite2012: Future challenges, sustainable futures (pp. 875-880)..

Stevenson, M. P., Hartmeyer, R., \& Bentsen, P. (2017). Systematically reviewing the potential of concept mapping technologies to promote self-regulated learning in primary and secondary science education. Educational Research Review, 21, 1-16. https://doi.org/10.1016/j.edurev.2017.02.002

Sung, Y.-T., Chang, K.-E., \& Yang, J.-M. (2015). How effective are mobile devices for language learning? A meta-analysis. Educational Research Review, 16, 68-84. https://doi.org/10.1016/j.edurev. 2015.09.001

Tricco, A. C., Lillie, E., Zarin, W., O’Brien, K. K., Colquhoun, H., Levac, D., ... Straus, S. E. (2018). PRISMA Extension for Scoping Reviews (PRISMA-ScR): Checklist and Explanation. Annals of Internal Medicine, 169(7), 467-473.https://doi.org/10.7326/M18-0850

Trinder, R. (2017). Informal and deliberate learning with new technologies. ELT Journal, 71(4), 401-412. https://doi.org/10.1093/elt/ccw117

Troussas, C., Virvou, M., \& Alepis, E. (2014). Collaborative learning: Group interaction in an intelligent mobile-assisted multiple language learning system. Informatics in Education, 13(2), 279-292. https://doi.org/10.15388/infedu.2014.17

Tsou, W., Wang, W., \& Tzeng, Y. (2006). Applying a multimedia storytelling website in foreign language learning. Computers \& Education, 47(1), 17-28. https://doi.org/10.1016/j.compedu.2004. 08.013

Ünal, S., Çeliköz, N., \& Sari, I. (2017). EFL proficiency in language learning and learner autonomy perceptions of Turkish learners. Journal of Education and Practice, 8(11), 117-122.

Vermunt, J. D., \& Donche, V. (2017). A learning patterns perspective on student learning in higher education: State of the art and moving forward. Educational Psychology Review, 29(2), 269-299. https://doi.org/10.1007/s10648-017-9414-6

Vogel, D., Kennedy, D., \& Kwok, R.C.-W. (2009). Does using mobile device applications lead to learning? Journal of Interactive Learning Research, 20(4), 469-485. 
Wharton, G. (2000). Language learning strategy use of bilingual foreign language learners in Singapore. Language Learning, 50(2), 203-243. https://doi.org/10.1111/0023-8333.00117

Wolters, C. A., \& Rosenthal, H. (2000). The relation between students' motivational beliefs and their use of motivational regulation strategies. International Journal of Educational Research, 33(7), 801820. https://doi.org/10.1016/S0883-0355(00)00051-3

Wrigglesworth, J., \& Harvor, F. (2018). Making their own landscape: Smartphones and student designed language learning environments. Computer Assisted Language Learning, 31(4), 437-458. https:// doi.org/10.1080/09588221.2017.1412986

Yao, S. (2016). Research on web-based autonomous English learning of engineering students. International Journal of Emerging Technologies in Learning, 11(06), 4. https://doi.org/10.3991/ijet.v11i06. 5802

Yot-Domínguez, C., \& Marcelo, C. (2017). University students' self-regulated learning using digital technologies. International Journal of Educational Technology in Higher Education, 14(1), 38. https:// doi.org/10.1186/s41239-017-0076-8

Zeynali, S. (2016). The effects of socio-affective strategy in the enhancement of reading comprehension among Iranian EFL learners. International Journal of Language and Linguistics, 4(2), 9. https://doi. org/10.11648/j.ijl1.s.2016040201.12

Zhang, D., \& Pérez-Paredes, P. (2019). Chinese postgraduate EFL learners' self-directed use of mobile English learning resources. Computer Assisted Language Learning, 1-26. https://doi.org/10.1080/ 09588221.2019 .1662455

Zhou, Y., \& Wei, M. (2018). Strategies in technology-enhanced language learning. Studies in Second Language Learning and Teaching, 8(2), 471-495. https://doi.org/10.14746/ssllt.2018.8.2.13

Zimmerman, B. J. (2000). Attaining self-regulation: A social cognitive perspective. In M. Boekaerts, P. R. Pintrich, \& M. Zeidner (Eds.), Handbook of self-regulation (pp. 13-39). Academic Press.

Zimmerman, B. J. (2008). Investigating self-regulation and motivation: Historical background, methodological developments, and future prospects. American Educational Research Journal, 45(1), 166183. https://doi.org/10.3102/0002831207312909

Zou, B., \& Yan, X. (2014). Chinese students' perceptions of using mobile devices for English learning. International Journal of Computer-Assisted Language Learning and Teaching, 4(3), 20-33.

Publisher's Note Springer Nature remains neutral with regard to jurisdictional claims in published maps and institutional affiliations. 